\title{
Comparison of atrial fibrillation ablation efficacy using remote magnetic navigation vs. manual navigation with contact-force control
}

\author{
Jiri Jez ${ }^{\mathrm{a}, \mathrm{b}}$, Tomasz Jadczyk $k^{\mathrm{a}, \mathrm{c}}$, Frantisek Lehara ${ }^{\mathrm{a}, \mathrm{b}}$, Martin Pes ${ }^{\mathrm{a}, \mathrm{b}, \mathrm{d}}$, Tomas Kulik ${ }^{\mathrm{a}}$, Silvie Belaskova ${ }^{\mathrm{e}}$, Filip Soucek ${ }^{\mathrm{a}}$, \\ Guido Caluori ${ }^{\mathrm{a}, \mathrm{f}}$, Wojciech Wojakowskic ${ }^{\mathrm{c}}$ Zdenek Starek ${ }^{\mathrm{a}, \mathrm{b}}$
}

\begin{abstract}
Aims. This study aims to compare procedural parameters and clinical efficacy of remote magnetic navigation (RMN) vs. manual navigation (MAN) approach for radiofrequency ablation (RFA) in patients with atrial fibrillation (AF).

Methods. 146 patients with AF were enrolled in the study. In the RMN group $(n=57)$, patients were treated with the CARTO $^{\circledR} 3$ in combination with the Niobe ES system. In the MAN group $(n=89)$, ablation was performed with the EnSite Velocity and TactiCath ${ }^{\text {TM }}$ Quartz catheter with direct contact force measurement. Procedural time, ablation time, fluoroscopy time, radiation dose and ablation counts were measured and compared between the groups. Recurrence of AF was evaluated after 6 months of follow-up.

Results. Mean procedure times ( $236.87 \pm 64.31$ vs. $147.22 \pm 45.19 \mathrm{~min}, P<0.05)$, counts of RF applications $(74.30 \pm 24.77 \mathrm{vs}$. $49.15 \pm 20.33, P<0.05)$ and total RFA times (4323.39 \pm 1426.69 vs. $2780.53 \pm 1157.85 \mathrm{~s}, P<0.05)$ were all significantly higher in the RMN than in the MAN group, respectively. In the same order, mean X-ray dose $(9722.6 \pm 7507.4$ vs. $8087.9 \pm 6051.5$ $\left.\mathrm{mGy} / \mathrm{cm}^{2}, P=0.12\right)$ and mean total X-ray exposure time $(8.07 \pm 4.20 \mathrm{vs}$. $9.54 \pm 5.47 \mathrm{~min}, P=0.08)$ were not statistically different. At 6-month follow-up, freedom from AF was similar in RMN and MAN group for paroxysmal $(60.8 \%$ and $73 \%$, respectively, $P=0.42)$ and persistent $A F(69.6 \%$ and $75.0 \%$, respectively, $P=0.77)$.

Conclusions. Due to the fact that mid-term clinical outcomes showed no significant differences in AF recurrences between groups and manual ablation strategy provided more favorable results regarding acute procedural parameters, we can conclude that the remote magnetic navigation is not superior to the manual approach.
\end{abstract}

Key words: atrial fibrillation, radiofrequency ablation, electro-anatomical mapping, remote magnetic navigation, contact-force technology

Received: May 20, 2019; Revised: July 19, 2019; Accepted: September 4, 2019; Available online: October 10, 2019

https://doi.org/10.5507/bp.2019.045

(c) 2020 The Authors; https://creativecommons.org/licenses/by/4.0/

anternational Clinical Research Center, Interventional Cardiac Electrophysiology, St. Anne's University Hospital Brno, Czech Republic ${ }^{b}$ Department of Cardiovascular Diseases, Faculty of Medicine, Masaryk University, Brno, Czech Republic

'Department of Cardiology and Structural Heart Diseases, Medical University of Silesia, Katowice, Poland

${ }^{d}$ Department of Biology, Faculty of Medicine, Masaryk University, Brno, Czech Republic.

eBiostatistics, International Clinical Research Center, St. Anne's University Hospital Brno, Brno, Czech Republic

${ }^{f}$ CEITEC, Masaryk University, Brno, Czech Republic

Corresponding author: Zdenek Starek, e-mail: starekzdenek@hotmail.com

\section{INTRODUCTION}

Currently, radiofrequency catheter ablation (RFA) is the most commonly used invasive treatment strategy for symptomatic, drug-resistant atrial fibrillation (AF). Conventionally, pulmonary vein isolation (PVI) is based on point-by-point lesion formation, applied by irrigated ablation catheters in power control mode ${ }^{1,2} .3 \mathrm{D}$ electroanatomical mapping (EAM) systems, such as the EnSite Velocity $^{\mathrm{TM}}$ (Abbott Inc) and CARTO ${ }^{\circledR} 3$ (Biosense Webster Inc), are routinely used to support complex electrophysiology procedures ${ }^{3}$. EAM-guided treatment can be performed with either manual (MAN) or by remote magnetic-navigated (RMN) catheters ${ }^{4}$. Concerning manual ablation, steerable sheaths and contact force (CF)-sensing catheters are widely used in clinical practice. CF-sensing catheters allow continuous and real-time measurement of catheter tip - myocardium contact, thus providing more reliable and effective energy delivery ${ }^{5,6}$. Procedure optimization strategy, aimed to increase freedom from AF and focused on CF-guided RFA safety and effectiveness, have been described in previous studies ${ }^{5,7-9}$. In recent years, robotic systems have been developed and introduced as clinical tools for arrhythmia treatment ${ }^{4,10-11}$. Niobe ES system (Stereotaxis Inc) is based on a homogeneous, permanent, and orientable magnetic field that guides intracardiac movements of the catheter with a magnetembedded tip. The system is convenient for mapping of challenging anatomies and ablations procedures ${ }^{12}$. Despite the fact that the RMN system reduces radiation doses for patients and doctors ${ }^{13}$, several previous studies reported that application of RMN was challenging in comparison to manual approach ${ }^{13,14}$. Procedural steps are associated with additional time required for patient preparation, sys- 
tem configuration and left atrium (LA) mapping/catheter ablation $^{15}$. At 1-year follow-up, freedom from AF/atrial flutter was demonstrated to be statistically non different among patients treated with MAN and RMN approach ${ }^{16}$. Due to patient pool heterogeneity in previously reported outcomes, this study aims to compare solely AF ablation performed with Niobe ES and remote magnetic-navigated Navistar ${ }^{\circledR}$ Thermocool ${ }^{\circledR}$ RMT catheter (Biosense Webster Inc) to standard CF-guided manual procedure using TactiCath ${ }^{\mathrm{TM}}$ Quartz catheter (Abbott Inc).

\section{MATERIALS AND METHODS}

This retrospective single-center study compared two groups of patients with pharmacoresistant symptomatic AF treated with RMN or MAN catheter ablation, both supported by EAM. In accordance to our electrophysiology laboratory logistics and workflow (Niobe ES system available in one room and NavX Velocity in another room), all patients were enrolled consecutively either to RMN or MAN group according to EP lab assignment for procedure. The study adhered to the principles of the Declaration of Helsinki.

\section{Preparation for procedure}

In each patient, AF diagnosis was documented by $12-$ lead ECG or ECG Holter monitoring (episode of AF lasting $\geq 30 \mathrm{~s}$ in duration) (ref. ${ }^{17}$ ). All participants had previously failed antiarrhythmic drug therapy. Moreover, all patients were effectively anticoagulated with warfarin (target international normalized ratio of 2 to 3 ) or directacting oral anticoagulants for more than 1 month. Atrial thrombi were excluded by pre-procedure transesophageal echocardiography.

After obtaining femoral vein access, a steerable catheter (Inquiry ${ }^{\mathrm{TM}}$, Abbott Inc) was positioned within the coronary sinus. Subsequently, transseptal puncture was performed with Agilis ${ }^{\mathrm{TM}}$ and SL1 ${ }^{\mathrm{TM}}$ (Abbott Inc) sheath advanced to the LA. A single bolus of 50-100 IU/ kg body weight of heparin with adequate continuous infusion was administered. The activated clotting time was evaluated every 20 min for additional heparin administration, aiming for value between 300-400 s.

In the MAN group, the SL1 ${ }^{\mathrm{TM}}$ and Agilis ${ }^{\mathrm{TM}}$ sheaths were used for introduction of a circular mapping duodecapolar catheter (Reflexion ${ }^{\mathrm{TM}}$, Abbott Inc) and CFsensing ablation catheter (TactiCath ${ }^{\mathrm{TM}}$ Quartz, Abbott Inc), respectively. A 3D electro-anatomical model of the LA was reconstructed with the circular catheter using the NavX Velocity system (Abbot Inc).

In the RMN group, the Agilis ${ }^{\mathrm{TM}}$ sheath was used for introduction of the magnetic ablation catheter (Navistar ${ }^{\circledR}$ Thermocool ${ }^{\circledR}$ RMT, Biosense Webster Inc) connected to the Niobe ES (Stereotaxis Inc) and controlled by QuikCAS ${ }^{\mathrm{TM}}$ system (Stereotaxis Inc), which allows remote catheter advancement and retraction. Endocardiumtip contact was ensured by proprietary algorithm in the e-Contact ${ }^{\mathrm{TM}}$ module (Stereotaxis Inc). A 3D electroanatomical model was generated with the CARTO ${ }^{\circledR} 3$
(Biosense Webster Inc). Finally, the circular mapping catheter (Reflexion ${ }^{\mathrm{TM}}$, Abbott Inc) was introduced via the SL1 ${ }^{\mathrm{TM}}$ sheath into the LA for monitoring of pulmonary veins (PVs) electrical activity.

MAN and RMN catheter ablations were performed by 2 experienced electrophysiologists. Attenuating learning curve effect, first $20 \mathrm{RMN}$-guided AF procedures were excluded from the analysis.

\section{Ablation strategy}

All patients underwent circumferential PVI. Additional linear lesions on the roof and mitral isthmus were applied in patients with the persistent form of AF.

In RMN group, anterior and posterior wall ablation was performed at $40 \mathrm{~W}$ and $35 \mathrm{~W}$, respectively. Preferably, if anatomically possible, dragging ablation technique was used to obtain continuous circumferential lines around ipsilateral PVs. In patients treated with MAN, point-bypoint strategy (maximum duration of 30 s energy delivery per point) was applied and successful point ablation was confirmed by change of local intracardiac ECG potentials. In this group, anterior wall ablation was carried out at $30 \mathrm{~W}$ and posterior wall ablation at $25 \mathrm{~W}$. For patients in sinus rhythm, persistent PVI and linear lesions block were verified by the stimulation technique. In individuals with AF, electrical cardioversion was performed at the end of the procedure and confirmation of persistent PVI, and blockage of linear lesions was assessed by targeted stimulation $^{18,19}$.

\section{Clinical follow-up}

6-month follow-up was based on 24-hour ECG Holter monitoring ${ }^{17}$ and ambulatory visit with the aim to evaluate patient's clinical status and assess potential recurrence of $\mathrm{AF}$ based on electrocardiography recording.

\section{Statistical analysis}

Statistical analysis was performed using SAS 9.3 (SAS Institute Inc) and was presented as the mean \pm standard deviation (SD) or as median value with $25^{\text {th }}-75^{\text {th }}$ interquartile range (IQR). Qualitative data were expressed as absolute values and/or percentages. Differences between groups were analyzed using the t-test for normally distributed data and the Mann-Whitney U test for non-normally distributed data. Categorical data were analyzed using chisquare test analysis or the Fisher exact test where appropriate. Data distribution was verified by the Shapiro-Wilk test. $P<0.05$ was considered to be statistically significant.

\section{RESULTS}

Overall, 449 patients were ablated for paroxysmal (ParAF) or persistent AF (PerAF) at our department between the $18^{\text {th }}$ of March 2015 and the $9^{\text {th }}$ of November 2016. Most of patients $(n=303)$ were found not eligible for the study primarily because they had been treated with different types of ablation catheters or had enrolled in other studies with a possible direct impact on monitored parameters. 
Table 1. Baseline characteristics of study groups.

\begin{tabular}{|c|c|c|c|}
\hline & $\begin{array}{c}\text { RMN group } \\
n=57\end{array}$ & $\begin{array}{c}\text { MAN group } \\
n=89\end{array}$ & $P$ \\
\hline Males, n (\%) & $41(71.93)$ & $68(76.40)$ & 0.54 \\
\hline Age, years $($ mean $\pm \mathrm{SD})$ & $63.6 \pm 17.6$ & $61.7 \pm 30.8$ & 0.19 \\
\hline Paroxysmal AF, n (\%) & $30(52.63)$ & $43(48.31)$ & 0.61 \\
\hline Persistent AF, n (\%) & $27(47.37)$ & $46(51.69)$ & 0.61 \\
\hline Structural heart diseases, $\mathrm{n}(\%)$ & $12(21.05)$ & $19(21.35)$ & 0.97 \\
\hline LA diameter (PLAX view), mm (mean \pm SD) & $47.58 \pm 12.42$ & $47.36 \pm 16.64$ & 0.85 \\
\hline BMI, $\mathrm{kg} / \mathrm{m}^{2}($ mean $\pm \mathrm{SD})$ & $29.08 \pm 8.80$ & $29.60 \pm 15.42$ & 0.55 \\
\hline LVEF, \% (mean \pm SD) & $56 \pm 17$ & $57 \pm 32$ & 0.68 \\
\hline Hypertension, n (\%) & $32(56.14)$ & $45(50.56)$ & 0.51 \\
\hline Diabetes mellitus, $\mathrm{n}(\%)$ & $15(26.31)$ & $18(20.22)$ & 0.40 \\
\hline
\end{tabular}

AF - atrial fibrillation, BMI - body mass index, LA - left atrium, LVEF - left ventricle ejection fraction, MAN - manual navigation, NS - nonsignificant, PLAX - parasternal long axis, RMN - remote magnetic navigation, SD - standard deviation

Table 2. Procedural parameters.

\begin{tabular}{|c|c|c|c|c|}
\hline & AF type & $\begin{array}{c}\text { RMN group } \\
n=57\end{array}$ & $\begin{array}{c}\text { MAN group } \\
n=89\end{array}$ & $P$ \\
\hline \multirow[t]{2}{*}{ Procedure time, $\min$} & ParAF & $212.0(178.0-236.0)$ & $142.0(118.0-151.0)$ & $<0.05$ \\
\hline & PerAF & $248.0(202.0-300.0)$ & $137.5(118.0-166.0)$ & $<0.05$ \\
\hline \multirow[t]{2}{*}{ X-ray exposure time, $\min$} & ParAF & $7.35(5.50-9.10)$ & $8.20(5.00-12.80)$ & 0.39 \\
\hline & PerAF & $6.20(5.20-10.90)$ & $9.25(5.80-12.30)$ & 0.22 \\
\hline \multirow[t]{2}{*}{ RFA time, $s$} & ParAF & $3664.0(2873.0-4441.0)$ & $2261.0(1779.0-3107.0)$ & $<0.05$ \\
\hline & PerAF & $4677.0(3807.0-6099.0)$ & $2764.5(2228.0-3396.0)$ & $<0.05$ \\
\hline \multirow[t]{2}{*}{ X-ray dose, $\mathrm{mGy} / \mathrm{cm}^{2}$} & ParAF & $7995.0(5986.0-10898.0)$ & $5951.0(3217.0-9916.0)$ & 0.13 \\
\hline & PerAF & $6731.0(4994.0-14143.0)$ & 7515.5 (4094.0-10757.0) & 0.45 \\
\hline \multirow[t]{2}{*}{ Count of RFA, $n$} & ParAF & $69.0(51.0-78.0)$ & $40.0(34.0-57.0)$ & $<0.05$ \\
\hline & PerAF & $83.0(53.0-103.0)$ & $45.5(40.0-58.0)$ & $<0.05$ \\
\hline \multirow[t]{2}{*}{ 6-month follow-up, freedom from AF episodes, n (\%) } & ParAF & 60.8 & 73 & 0.42 \\
\hline & PerAF & 69.6 & 75 & 0.77 \\
\hline
\end{tabular}

AF - atrial fibrillation, MAN - manual navigation, NS - non-significant, ParAF - paroxysmal atrial fibrillation, PerAF - persistent atrial fibrillation, RFA - radiofrequency ablation, RMN - remote magnetic navigation

Therefore, for the presented analysis, 146 patients were included, presenting in equal share with ParAF and PerAF (73 each). Regarding treatment strategy, 57 and 89 patients underwent RMN and MAN guided RFA procedures, respectively. Baseline clinical characteristics was not significantly different between groups (Table 1). In the RMN and MAN group, mean age was $63.6 \pm 17.6$ and $61.7 \pm 30.8$ years with $71.9 \%$ and $76.4 \%$ of male participants, respectively. Moreover, $52.6 \%$ and $44.9 \%$ of individuals in the RMN and MAN group were diagnosed with the ParAF, respectively, while the remaining patients suffered from PerAF. Prevalence of adverse events postprocedure was identical among groups (in each cohort 1 case of post-catheterization femoral artery pseudoaneurysm treated with percutaneous thrombin injection).

Mean procedure time was significantly longer in the RMN than in the MAN group (236.87 \pm 64.31 vs. $147.22 \pm 45.19 \mathrm{~min}$, respectively, $P<0.05)$. Counts of RF applications $(74.30 \pm 24.77$ vs. $49.15 \pm 20.33, P<0.05)$ and total RFA times $(4323.39 \pm 1426.69$ vs. $2780.53 \pm 1157.85 \mathrm{~s}$, $P<0.05$ ) were also statistically significantly greater in the RMN group. Mean X-ray dose for RMN and MAN group
(9722.6 \pm 7507.4 vs. $8087.9 \pm 6051.5 \mathrm{mGy} / \mathrm{cm}^{2}$, respectively, $P=0.12)$, together with mean total $\mathrm{X}$-ray exposure time (8.07 \pm 4.20 and $9.54 \pm 5.47 \mathrm{~min}$, respectively, $P=0.08)$ were not statistically different (Table 2). MAN- and RMNguided catheter ablation procedures are representatively illustrated in Fig 1 and Fig 2.

Procedurally, to confirm the durability of the bidirectional electrical block between PVs and the LA, the entry/ exit stimulation was performed for each PVs after 15-20 min post-ablation using circular mapping duodecapolar catheter (Reflexion ${ }^{\mathrm{TM}}$, Abbott Inc).

Moreover, in patients with PerAF treated with RMN and MAN approach, roof line was bidirectionally tested with block confirmation in $65 \%$ and $82.8 \%$, respectively, $P=0.44$. Moreover, the mitral isthmus line was bidirectionally tested with block confirmation in $31.58 \%$ and $43.75 \%$, respectively, $P=0.39$.

After 6 months post-RFA, 18 participants were lost from follow-up. In patients diagnosed with ParAF, freedom from AF episodes was not statistically different between groups $(60.8 \%$ and $73 \%$ in $\mathrm{RMN}$ and MAN group, respectively, $P=0.42$ ). Similarly, no statistically 
significant differences in efficacy of evaluated ablation approaches were observed in PerAF group after 6 months, where $69.6 \%$ subjects treated with RMN and $75 \%$ individuals treated with MAN were free from AF recurrence $(P=0.77)$.

\section{DISCUSSION}

Over the last decade, a significant technological advancement has been made in the management of $\mathrm{AF}$ patients, with a special focus on 3D EAM and remotelynavigated PVI (ref. $\left.{ }^{4}\right)$. FDA-approved EAM technology has been consistently developed and marketed by medical product manufacturers such as Abbott (NavX), Biosense Webster (CARTO) and Boston Scientific (Rhytmia). Importantly, open-irrigated tip catheters with a real-time catheter-tissue CF measurement function (TactiCath ${ }^{\mathrm{TM}}$ Quartz, Abbott and ThermoCool SmartTouch ${ }^{\circledR}$, Biosense Webster) became available, improving efficacy and safety of ablation procedures ${ }^{20}$. Contact sensing estimation is also available, albeit without direct $\mathrm{CF}$ quantification, for RMN procedures (e-Contact, Stereotaxis Inc).

Currently, among magnetic remote navigation solutions, the Stereotaxis Niobe system is clinically used. Previously published studies provide inconclusive data regarding the utility of the RMN in comparison to standard manual approach suggesting that MAN-guided RFA was associated with shorter ablation times ${ }^{10,15,21}$ and higher success rates of PVI (ref. ${ }^{15,22}$ ). By contrast, Yuan et al. found superiority for RMN over the MAN strategy with respect to mid- and long-term (up to 3.5 years) outcomes measured by: AF-free rate and clinical improvement, shorter fluoroscopy time, and no significant differences in terms of total procedure time ${ }^{23}$. With respect to remote navigation, clinical data confirmed reduced radiation exposure for patients and doctors ${ }^{13}$. Nevertheless, there has been no consensus regarding optimal treatment strategy because of the heterogeneity of protocols (i.e., catheter types, measured parameters, end points) used in a relatively small number of studies.

In the presented study, RMN and MAN approach were retrospectively confronted across two selected patients' cohorts with no statistically significant difference in clinical history. Moreover, both RFA strategies were assisted by two non-fluoroscopic cardiac mapping systems, EnSite Velocity ${ }^{\mathrm{TM}}$ and CARTO ${ }^{\circledR} 3$, both of which are designed to provide precise anatomical and local electrical information (i.e., local activation time and unipolar/ bipolar voltage measurements).

Our study showed that 6 months post PVI, there was no statistical difference in arrhythmia recurrence rate in patients with ParAF and PerAF who underwent RMN or MAN procedure. This results accord with two meta-analyses by Bradfield et al. ${ }^{13}$ and Proietti et al. ${ }^{14}$, however, our result must be interpreted with caution due to relatively small number of patients and retrospective study design. Moreover, the abovementioned meta-analyses ${ }^{13,14}$ revealed that the RMN-guided RFA is associated with a longer

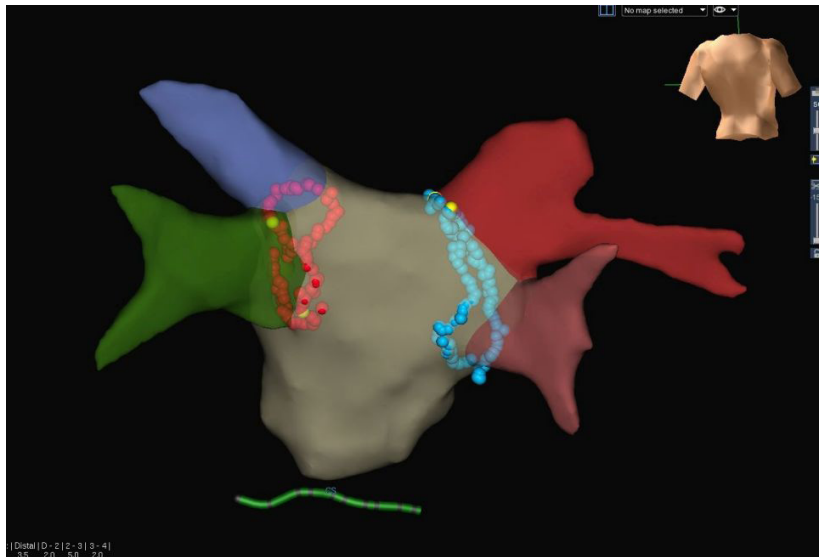

Fig. 1. Manual navigation-guided catheter ablation.

3D electro-anatomical map of the left atrium during ablation of paroxysmal atrial fibrillation using system EnSite Velocity from postero-anterior view. Red and blue dots highlight circular radiofrequency ablation lesions around the left and right pulmonary veins respectively. Yellow dots are places of isolation of the pulmonary veins.

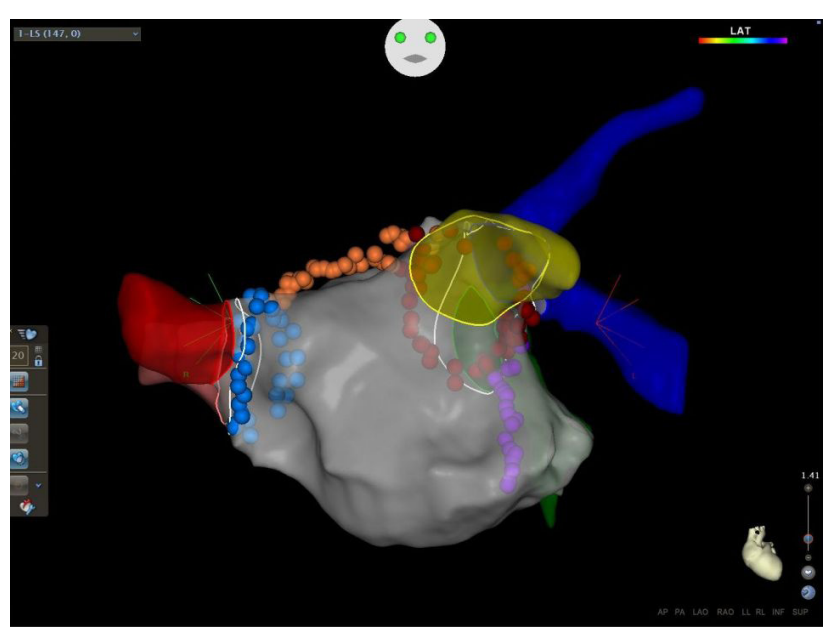

Fig. 2. Remote magnetic navigation-guided catheter ablation. 3D electro-anatomical map of the left atrium during ablation of persistent atrial fibrillation using system CARTO ${ }^{R} 3$ from antero-posterior view. Red and blue dots highlight circular radiofrequency ablation lesions around the left and right pulmonary veins respectively, orange dots highlight roof ablation line and violet dots highlight mitral isthmus line.

overall procedure duration. We observed the same procedural features in our study, and this was attributed to:

(1) Configuration and set-up

a. EAM system (CARTO patch placement and position calibration)

b. Stereotaxis system (preparation of the catheter-advancing device, magnet set-up, and need for manual repositioning of the circular catheter during the procedure)

(2) The use of low-density 2-pole catheter for mapping in RMN group. Correspondingly, duodecapolar map- 
ping catheter was used during MAN procedures, which reduced LA mapping time

(3) RMN procedure performed without Vdrive ${ }^{\mathrm{TM}} / \mathrm{V}$ Loop $^{\mathrm{TM}}$ system for remote navigation of circular mapping catheter; necessity of manual placement of the circular mapping catheter to different PVs during the procedure for conduction block confirmation

Our study results are in line with multi-center German ablation registry data published by van den Bruck et al. ${ }^{24}$. Sub-cohort analysis included 2442 patient undergoing AF catheter ablation using MAN (89\%), RMN (3.3\%) and Sensei robotic navigation system (Hansen Medical Inc) (7.7\%). Authors concluded that remotely navigated systems are safe providing high acute success ablation rate. Regarding mapping and ablation parameters, procedure duration time was $150 \mathrm{~min}$ (120-200 $\mathrm{min}$ ) and $265 \mathrm{~min}$ (210-305 $\mathrm{min}$ ) for MAN and RMN, respectively. Novel systems were associated with reduced fluoroscopy exposure and higher radiofrequency energy delivery. It is worth noting however, that the registry included few RMN procedures ( 80 out of 2442) over the course of $\sim 3$ years (July 2008 - May 2011) (ref. ${ }^{24}$ ) and technology has advanced since that time. Furthermore, similar to our study, Lim et al. retrospectively analysed 443 consecutive AF patients (229 MAN and 214 RMN cases). Attenuating learning curve effect for RMN procedures, total procedural time was $186.3 \pm 65.6$ in MAN and $249.5 \pm 65.5 \mathrm{~min}$ in RMN group, with comparable acute procedural success rate and number of procedure-related complications ${ }^{25}$.

Interestingly, Lin et al. described an initial experience using the EnSite Precision (Abbott Inc), that integrates magnetic and impedance technology $\left(\mathrm{CARTO}^{\circledR} 3\right.$ equivalent), combined with a circular magnetic catheter (Advisor $^{\mathrm{TM}} \mathrm{FL}$, Sensor Enabled ${ }^{\mathrm{TM}}$, Abbott Inc) for manual mapping and open-irrigated magnetic catheter (Celsius ${ }^{\circledR}$ ThermoCool ${ }^{\circledR}$ RMT, Biosense Webster Inc) for ablation. This novel EAM system was compared to the CARTO ${ }^{\circledR} 3$, applying an open-irrigated, magnetic catheter (Navistar ${ }^{\circledR}$ Thermocool ${ }^{\circledR}$ RMT, Biosense Webster Inc) for mapping and ablation. In both groups, RMN Niobe ES was used. The authors concluded that there were no significant differences in procedure parameters between the EnSite Precision and the CARTO ${ }^{\circledR} 3$; the overall procedure durations were $117.9 \pm 29.6$ and $119.2 \pm 29.7 \mathrm{~min}$, ablation times were $28.0 \pm 12.9$ and $27.9 \pm 15.8 \mathrm{~min}$, and fluoroscopy time were $6.1 \pm 2.4$ and $4.8 \pm 2.2 \mathrm{~min}$, respectively ${ }^{26}$.

In our opinion, AF treatment strategy should be in line with a particular EP lab operation mode. Medical-logistic decision must be balanced, taking into consideration:

(1) The type of treated arrhythmias (RMN is an excellent tool for ventricular arrhythmias, especially for complex anatomy in patients with congenital heart defects) (ref. ${ }^{27,28}$ )

(2) Clinical experience of electrophysiologists in a specific method, since remote navigation requires specialized training further than conventional RFA

(3) Financial aspects, due to the extensive cost of the machinery and system installation
Operator clinical experience is especially important factor. All RMN and MAN catheter ablations were performed by two cardiac electrophysiologists, with more than 10 years of clinical experience each. Noteworthy, in our center, since 2015, all ventricular arrhythmia cases are treated using Niobe ES system navigated by the same operators, who carried out RFA in patients enrolled to the presented study.

It is important to note that this work has several inherent limitations. The first is the retrospective single-center character of the study. Secondly, the number of enrolled patients was relatively small. We did not perform a quantitative evaluation of X-ray exposure of the medical staff involved in catheter ablations performance. We did not account for different inherent mapping time when employing a quadripolar catheter (RMN) versus a duodecapolar one (MAN). This pivotal study limitation could be overcome using the Vdrive ${ }^{\mathrm{TM}}$ with V-Loop ${ }^{\mathrm{TM}}$ system allowing remote navigation of circular mapping catheters. In comparison to manual PVI procedures, Nölker et al. demonstrated non-inferiority of the Vdrive/V-Loop technology in regard to procedure safety and clinical effectiveness ${ }^{29}$. It is important to note that different power setting were used in RMN and MAN groups for ablation (10 Watts higher power in RMN group as recommended by Stereotaxis Inc.), however, contact force data were not reported in the presented study. Finally, the recurrence of AF was assessed 6-month post-RFA procedure during ambulatory follow-up visit using 12-lead ECG and 24-hour ECG Holter. More detailed and longer clinical observation especially with more detailed monitoring using implantable loop recorder might have revealed asymptomatic recurrences reflecting true success rate. The number of "lost to follow-up" patients (18 individuals) could be reduced using a telemedical reminder system based on automatic phone calls or SMS technology. Regarding above mentioned limitations, randomized, multi-center clinical trial, with comparable mapping catheters, should be carried out to evaluate clinical usability of RMN approach for AF.

\section{CONCLUSIONS}

AF catheter ablation procedures employing Niobe ES remote magnetic navigation system are not more clinically effective than the manual strategy, as freedom from AF at 6-month follow-up was not significantly different between groups. Moreover, in comparison to RMN, MAN-guided catheter ablation of AF showed favorable results in terms of certain peri-procedural parameters.

\section{ABBREVIATIONS}

AF, Atrial fibrillation; CF, Contact sensing; EAM, Electro-anatomical mapping; IQR, Interquartile rang; LA, Left atrium; LVEF, Left ventricle ejection fraction; MAN, Manual navigation; ParAF, Paroxysmal atrial fibrillation; PerAF, Persistent atrial fibrillation; PLAX, Parasternal long axis; PVI, Pulmonary veins isolation; 
PVs, Pulmonary veins; SD, Standard deviation; RF, Radiofrequency; RFA, Radiofrequency ablation; RMN, Remote magnetic navigation.

Acknowledgements: Supported by the Ministry of Education, Youth and Sport of the Czech Republic (project no. LQ1605 from the National Program of Sustainability II), Ministry of regional development of the Czech Republic (no. CZ.1.05/1.1.00/02.0123), and Masaryk University, Faculty of Medicine, Kamenice 5, 62500 Brno, Czech Republic.

Authors contributions: JJ: literature search, study design, data collection, data analysis, manuscript writing; TJ, GC: manuscript writing, data analysis, data interpretation; FL, MP, TK,FS: data collection; SB: data analysis, data interpretation; WW: critical review; ZS: study design, final approval of the version to be published.

Conflict of interest statement: The authors declare that there are no conflicts of interest regarding the publication of this paper.

\section{REFERENCES}

1. Macle L, Jais P, Weerasooriya R, Hocini M, Shah DC, Choi KJ, Scavee C, Raybaud F, Clementy J, Haissaguerre M. Irrigated-tip catheter ablation of pulmonary veins for treatment of atrial fibrillation. J Cardiovasc Electrophysiol 2002;13(11):1067-73.

2. Cappato R, Calkins H, Chen SA, Davies W, lesaka Y, Kalman J, Kim YH, Klein G, Natale A, Packer D, Skanes A, Ambrogi F, Biganzoli E. Updated worldwide survey on the methods, efficacy, and safety of catheter ablation for human atrial fibrillation. Circ Arrhythm Electrophysiol 2010;3(1):32-8.

3. Calkins H, Hindricks G, Cappato R, Kim YH, Saad EB, Aguinaga L, Akar JG, Badhwar V, Brugada J, Camm J, Chen PS, Chen SA, Chung MK, Nielsen JC, Curtis AB, Davies DW, Day JD, d'Avila A, de Groot N, Di Biase L, Duytschaever M, Edgerton JR, Ellenbogen KA, Ellinor PT, Ernst S, Fenelon G, Gerstenfeld EP, Haines DE, Haissaguerre M, Helm $\mathrm{RH}$, Hylek E, Jackman WM, Jalife J, Kalman JM, Kautzner J, Kottkamp $\mathrm{H}$, Kuck KH, Kumagai K, Lee R, Lewalter T, Lindsay BD, Macle L, Mansour M, Marchlinski FE, Michaud GF, Nakagawa H, Natale A Nattel S, Okumura K, Packer D, Pokushalov E, Reynolds MR, Sanders $P$, Scanavacca M, Schilling R, Tondo C, Tsao HM, Verma A, Wilber DJ, Yamane T. 2017 HRS/EHRA/ECAS/APHRS/SOLAECE expert consensus statement on catheter and surgical ablation of atrial fibrillation. Heart Rhythm 2017;14(10):e275-e444.

4. Pappone C, Vicedomini G, Manguso F, Gugliotta F, Mazzone P, Gulletta S, Sora N, Sala S, Marzi A, Augello G, Livolsi L, Santagostino A, Santinelli V. Robotic magnetic navigation for atrial fibrillation ablation. J Am Coll Cardiol 2006;47(7):1390-400.

5. Reddy VY, Shah D, Kautzner J, Schmidt B, Saoudi N, Herrera C, Jais $P$, Hindricks G, Peichl P, Yulzari A, Lambert H, Neuzil P, Natale A, Kuck $\mathrm{KH}$. The relationship between contact force and clinical outcome during radiofrequency catheter ablation of atrial fibrillation in the TOCCATA study. Heart Rhythm 2012;9(11):1789-95.

6. Kuck KH, Reddy VY, Schmidt B, Natale A, Neuzil P, Saoudi N, Kautzner J, Herrera C, Hindricks G, Jais P, Nakagawa H, Lambert H, Shah DC. A novel radiofrequency ablation catheter using contact force sensing: Toccata study. Heart Rhythm 2012;9(1):18-23.

7. Neuzil P, Reddy VY, Kautzner J, Petru J, Wichterle D, Shah D, Lambert $\mathrm{H}$, Yulzari A, Wissner E, Kuck KH. Electrical reconnection after pulmonary vein isolation is contingent on contact force during initial treatment: results from the EFFICAS I study. Circ Arrhythm Electrophysiol 2013;6(2):327-33.

8. Yokoyama K, Nakagawa H, Shah DC, Lambert H, Leo G, Aeby N, Ikeda A, Pitha JV, Sharma T, Lazzara R, Jackman WM. Novel contact force sensor incorporated in irrigated radiofrequency ablation catheter predicts lesion size and incidence of steam pop and thrombus. Circ Arrhythm Electrophysiol 2008;1(5):354-62.

9. Kimura M, Sasaki S, Owada S, Horiuchi D, Sasaki K, Itoh T, Ishida Y, Kinjo T, Tomita H, Okumura K. Comparison of lesion formation between contact force-guided and non-guided circumferential pulmonary vein isolation: a prospective, randomized study. Heart Rhythm 2014;11(6):984-91.

10. Miyazaki S, Shah AJ, Xhaet O, Derval N, Matsuo S, Wright M, Nault I, Forclaz A, Jadidi AS, Knecht S, Rivard L, Liu X, Linton N, Sacher F, Hocini $M$, Jais $P$, Haissaguerre $M$. Remote magnetic navigation with irrigated tip catheter for ablation of paroxysmal atrial fibrillation. Circ Arrhythm Electrophysiol 2010;3(6):585-9.

11. Aksu T, Bozyel S, Golcuk E, Yalin K, Guler TE. Atrial Fibrillation Ablation Using Magnetic Navigation Comparison With Conventional Approach During Long-Term Follow-Up. J Atr Fibrillation 2015;8(3):1276.

12. Roy K, Gomez-Pulido F, Ernst S. Remote Magnetic Navigation for Catheter Ablation in Patients With Congenital Heart Disease: A Review. J Cardiovasc Electrophysiol 2016;27 Suppl 1:S45-56.

13. Bradfield J, Tung R, Mandapati R, Boyle NG, Shivkumar K. Catheter ablation utilizing remote magnetic navigation: a review of applications and outcomes. Pacing Clin Electrophysiol 2012;35(8):1021-34.

14. Proietti $R$, Pecoraro $V$, Di Biase $L$, Natale $A$, Santangeli $P$, Viecca M, Sagone A, Galli A, Moja L, Tagliabue L. Remote magnetic with open-irrigated catheter vs. manual navigation for ablation of atrial fibrillation: a systematic review and meta-analysis. Europace 2013;15(9):1241-8.

15. Arya A, Zaker-Shahrak R, Sommer P, Bollmann A, Wetzel U, Gaspar T, Richter S, Husser D, Piorkowski C, Hindricks G. Catheter ablation of atrial fibrillation using remote magnetic catheter navigation: a case-control study. Europace 2011;13(1):45-50.

16. Weiss JP, May HT, Bair TL, Crandall BG, Cutler MJ, Day JD, Osborn JS, Mallender C, Bunch TJ. A Comparison of Remote Magnetic Irrigated Tip Ablation versus Manual Catheter Irrigated Tip Catheter Ablation With and Without Force Sensing Feedback. J Cardiovasc Electrophysiol 2016;27 Suppl 1:S5-S10.

17. Hsieh TT, Lee M, Huang WY, Tang SC, Sung SF, Chang KH, Lee JD, Lee TH, Huang YS, Jeng JS, Chung CM, Wu YL, Ovbiagele B. Atrial fibrillation trial to evaluate real-world procedures for their utility in helping to lower stroke events (AFTER-PULSE): Study protocol for a randomized controlled trial. Contemp Clin Trials Commun 2017;6:127-30.

18. Wang XH, Shi HF, Sun YM, Gu JN, Zhou L, Liu X. Circumferential pulmonary vein isolation: the role of key target sites. Europace 2008;10(2):197-204.

19. Haissaguerre $M$, Jais $P$, Shah DC, Takahashi A, Hocini M, Quiniou G, Garrigue S, Le Mouroux A, Le Metayer P, Clementy J. Spontaneous initiation of atrial fibrillation by ectopic beats originating in the pulmonary veins. N Engl J Med 1998;339(10):659-66.

20. Lin T, Ouyang F, Kuck KH, Tilz R. THERMOCOOL(R) SMARTTOUCH(R) CATHETER - The Evidence So Far for Contact Force Technology and the Role of VISITAG MODULE. Arrhythm Electrophysiol Rev 2014;3(1):44-7.

21. Luthje L, Vollmann D, Seegers J, Dorenkamp M, Sohns C, Hasenfuss $\mathrm{G}$, Zabel M. Remote magnetic versus manual catheter navigation for circumferential pulmonary vein ablation in patients with atrial fibrillation. Clin Res Cardiol 2011;100(11):1003-11.

22. Bauernfeind T, Akca F, Schwagten B, de Groot N, Van Belle Y, Valk S, Ujvari B, Jordaens L, Szili-Torok T. The magnetic navigation system allows safety and high efficacy for ablation of arrhythmias. Europace 2011;13(7):1015-21.

23. Yuan S, Holmqvist F, Kongstad O, Jensen SM, Wang L, Ljungstrom E, Hertervig $\mathrm{E}$, Borgquist R. Long-term outcomes of the current remote magnetic catheter navigation technique for ablation of atrial fibrillation. Scand Cardiovasc J 2017;51(6):308-15.

24. van den Bruck JH, Sultan A, Luker J, Thomas D, Willems S, Weinmann K, Kuniss M, Hochadel M, Senges J, Andresen D, Brachmann J, Kuck $\mathrm{KH}$, Tilz R, Steven D. Remote vs. conventional navigation for catheter ablation of atrial fibrillation: insights from prospective registry data. Clin Res Cardiol 2019;108(3):298-308.

25. Lim PCY, Toh JJH, Loh J, Lee ECY, Chong DTT, Tan BY, Ho KL, Ching CK, Teo WS. Remote magnetic catheter navigation versus conventional ablation in atrial fibrillation ablation: Fluoroscopy reduction. J Arrhythm 2017;33(3):167-71. 
26. Lin C, Pehrson S, Jacobsen PK, Chen X. Initial experience of a nove mapping system combined with remote magnetic navigation in the catheter ablation of atrial fibrillation. J Cardiovasc Electrophysiol 2017;28(12):1387-92.

27. Turagam MK, Atkins D, Tung R, Mansour M, Ruskin J, Cheng J, Di Biase L, Natale A, Lakkireddy D. A meta-analysis of manual versus remote magnetic navigation for ventricular tachycardia ablation. J Interv Card Electrophysiol 2017;49(3):227-35
28. Da Costa A, Guichard JB, Romeyer-Bouchard C, Gerbay A, Isaaz K. Robotic magnetic navigation for ablation of human arrhythmias. Med Devices (Auckl) 2016;9:331-9.

29. Nolker G, Schwagten B, Deville JB, Burkhardt JD, Horton RP, Sha Q, Tomassoni G. Vdrive Evaluation of Remote Steering and Testing in Lasso Electrophysiology Procedures Study: The VERSATILE Study in Atrial Fibrillation Ablation. J Cardiovasc Electrophysiol 2016;27 Suppl 1:S17-22 